\title{
Cervical Cardiac Ectopia in Cattle - a Case Report
}

\author{
Dana Liana PUSTA ${ }^{1}$, Rodica SOBOLU ${ }^{2}$, Adela BODEA ${ }^{3}$, Alexandra TĂBĂRAN ${ }^{1}$, Pompei BOLFĂ ${ }^{1}$, Ioan \\ PAŞCA ${ }^{1}$, Liviu BOGDAN ${ }^{1}$ \\ ${ }^{1}$ Department of Veterinary Medicine, USAMV Cluj-Napoca, Romania ${ }^{2}$ Department of Horticulture. USAMV \\ Cluj-Napoca, Romania ${ }^{3}$ Private Practitioner, Cluj-Napoca, Romania \\ *Corresponding author: dana.pusta@usamvcluj.ro
}

Bulletin UASVM Veterinary Medicine 72(2) / 2015,

Print ISSN 1843-5270; Electronic ISSN 1843-5378

DOI:10.15835/buasvmcn-vm: 11444

\begin{abstract}
The cardiac ectopia is a congenital disorder, characterized by the location of the heart outside the thoracic cavity. This disorder results due to an error during the maturation of medial line of the mesoderm and of the formation of ventral wall of the body during the embryonic development. The aetiology is not well known being considered the involving of genetic and environmental factors. The most important genetic factors involved in the heart ectopia are considered family Hox genes and the proto-oncogenes, which are generally involved in the induction and differentiation of the embryonic structures and the family Pax genes, which are involved in the growing and development of the organs, being considered as master genes, controlling the activity of other subordinate genes. The location of ectopia is very often ventral cervical, but there were also recorded cases of sternal (thoracic) and very rare the abdominal one (Abi and Giamberti, 2008; Wyrost, 1981).

The purpose of this study is to emphasize the clinical signs, diagnosis of the cervical heart ectopia and to establish the possible genetic prevention methods of this disorder.

The study was carried out on a two days old calf, which presented the clinical signs of heart ectopia. At palpation, the clinical examination emphasized a modified area in volume at the cervical level and the auscultation revealed the heart beats. At necropsy, patent ductum arteriosus was diagnosed, together with the stenosis of the aorta and bilateral heart hypertrophia.

In order to avoid the congenital pathological modifications of this type it is very important the checking of the sperm quality, both in the case of artificial and natural inseminations. It is very important, especially in the case of beef breeds to avoid the breeding between half-sisters or brothers or between the parents and their offspring. In order to test the genitors for their potential of gene carriers the testcross is recommended and the elimination of the carriers from the genitor group.
\end{abstract}

Keywords: cervical cardiac ectopia, cattle, genetic prophylaxis, multi-factorial disorder, polygenical determinism

\section{INTRODUCTION}

The cardiac ectopia is a congenital disorder, characterized by the location of the heart outside the thoracic cavity. This disorder results due to an error during the maturation of the medial line of the mesoderm and of the formation of the ventral wall of the body during the embryonic development. The aetiology is not well known being considered the involving of the genetic and environmental factors. Very often, the heart ectopia is located in the ventral cervical area, but there were also recorded cases of Bowen (1962). The most frequent one is the cervical location in $82 \%$ of the cases, followed by thoracical one in $14 \%$ of cases and the most seldom one is the abdominal location in 3\% of the cases (Wyrost, 1981).

Among the domestic animals, the heart ectopia is most frequent in cattle. There are certain numbers of factors, which may disturb 
the embryonic development determining heart ectopia. The product of conception may be exposed to different harmful agents starting with the pre-embryonic development, during embryonic development and also during the foetal one and its vulnerability depends on the development stage. For instance, during the pre-embryonic stage the embryo is very resistant to the action of various teratogenic factors because the pelucida membrane acts like a very efficient barrier against many viruses. The embryonic stage, in which a rapid growth and cellular differentiation is made, is more susceptible to the action of teratogenic factors. The congenital defects are produced by different factors, such as the genetically ones (genical or chromosomal abnormalities), chemical products (ethanol, cocaine and mercury), teratogenical plants (Veratum californicum), different types of radiations from the environment and infectious agents (viruses, bacteria, protozoa such as BVD/MD in cattle) (Radostitis et al., 2007). These teratogenic factors can induce a large range of malformations and/ or development defects. The confirmation of each factor involved requests many studies. For instance, the confirmation of a genetic defect and of its inheritance pattern is possible to be made by testcross between the individuals, which are suspected as carriers of the undesirable genes. The most important genetic factors involved in the heart ectopia are considered family Hox genes and the proto-oncogenes, which are generally involved in the induction and the differentiation of the embryonic structures, and the family Pax genes, which are involved in the growing and development of the organs, being considered as master genes, controlling the activity of other subordinate genes.

There are some case reports regarding the heart ectopia in cattle in which the location, direction and the heart shape, were almost similar (Hiraga and Abe, 1986). In all the cases, the longer axis of the heart was cranial - dorsal rotated at an angle of $180^{\circ}$, and the shape of the heart top was rounded, compared to the normal shape.

Some animals with heart ectopia can survive until they reach the maturity. In a general study a number of 42 calves survived more than six weeks, 40 of these being with cervical heart ectopia. One case of heart ectopia survived until the age of 14 , and another case had a normal gestation and parturition. The acute cardiac failure may occur when the animals are submitted to physical stress, such as the first parturition. (Radostitis et al., 2007).

In each case, the possible cause of the ectopia must be evaluated, which can be: the genetic disorders (genical or chromosomal), breed, teratogenical plant consumption, medication, the evolution of some infectious diseases, the level of radiation and so on. Until now there are no records regarding the existence of some direct correlations between the possible causes and the cardiac ectopia.

The causes of the congenital heart defects are still unknown but it is assumed that they are produced by some development disorders during the prenatal development determined by recessive genes or by the interactions between different genes, case in which the determinism is a polygenic one.

The purpose of this study is to emphasize the clinical signs, diagnosis of the cervical heart ectopia and to establish the possible genetic prevention methods of this disorder.

\section{MATERIALS AND METHODS}

The study was carried out on a two days old calf, which presented the clinical signs of cervical heart ectopia, manifested by the location of heart outside the thoracic cavity, in the ventral cervical area. The clinical exam was performed by auscultation and inspection. It was also performed an ultrasound exam in order to confirm the diagnose. After the death of the animal, which occur within a few hours after the clinical exam, the necropsy was made. The opening of the body was made by an incision of the ventral part, starting from the mandibular arch to the vulva. The skin was partially removed, and the ectopic heart was identified in cervical ventral area, located under the skin and the muscles of the above mentioned area. All organs in the thorax were examined. The necropsy of the thorax was followed by the necropsy of the abdominal cavity.

\section{RESULTS AND DISCUSSION}

The studied calf was a Charolaise crossbreed of two days of age. The clinical exam revealed the suspicious of heart ectopia because of the missing of heartbeats in the thoracic region and the presence of a deformation in cervical region (Fig. 1). At inspection, the heartbeats were visualized 
in the cervical region. The body weight was accordingly to the age being $36.9 \mathrm{~kg}$, but the thorax was narrowed compared to the normal developed calves. An ultrasound exam was performed in the cervical area, which confirmed the presence of the heart in this region and confirmed the diagnosis of cardiac ectopia or ectopia cordis cervicalis

Shortly after the clinical exam, the calf died and it was submitted to further patho-morphological examinations.

The necropsy exam revealed significant changes, both to the heart level and also to some other neighbouring organs. It was noticed a moderate subcutaneous oedema in the cervical region and the heart was identified in ventral cervical region, under the skin and muscles from the area (Fig. 2). The axis of heart was rotated with $180^{\circ}$, so that its apex was cranial-dorsal oriented to the head of the calf. The apex was rounded compared to the normal shape (Fig. 3).

Patent ductum arteriosus (Fig. 4A), persistent interatrial hole (Fig. 4B), aortic stenosis and

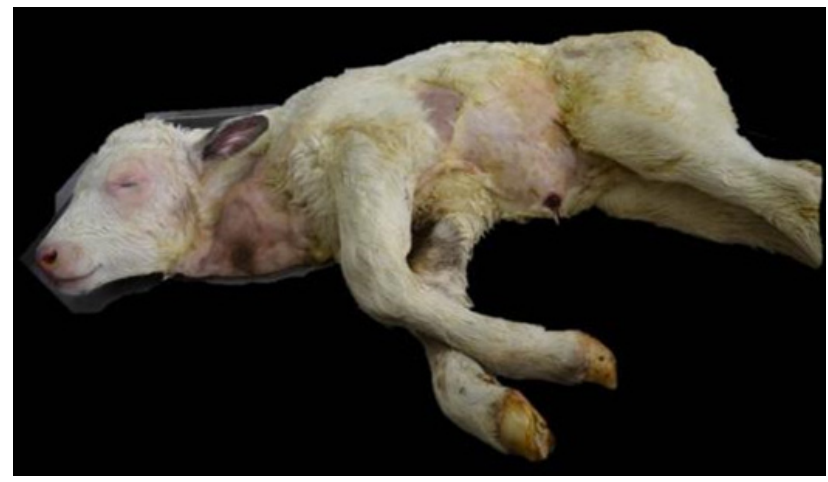

Fig. 1. Calf with cervical cardiac ecopia- exterior ectopia cordis cervicalis

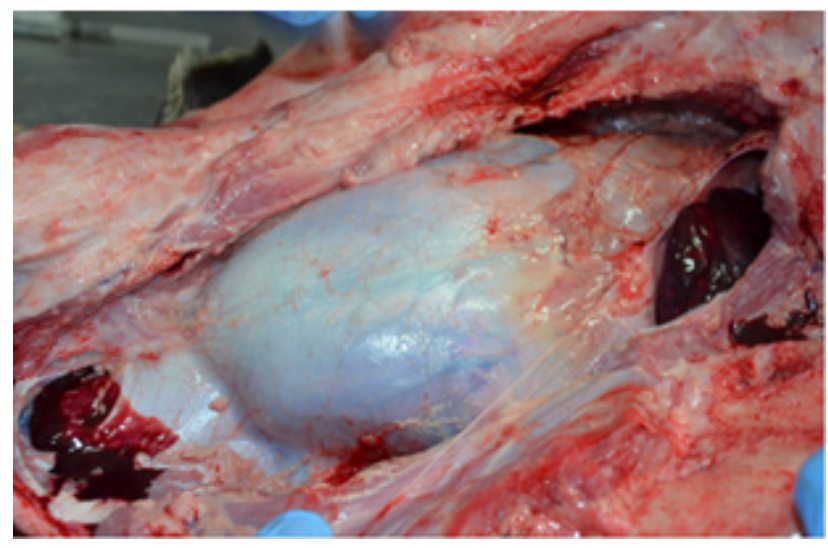

Fig. 2. The ectopic heart in the cervical ventral region bilateral concentric cardiac hypertrophy were identified (Fig. 4C). The thorax was narrowed compared to a normal one, and the breastbone was narrowed and irregular (Fig. 5). The majority of the veins presented a varicose aspect.

At the opening of the pericardium it was noticed a serous-hemorrhagic liquid, $10 \mathrm{ml}$. The changes at the pulmonary level were congestion of the pulmonary lobes and torsion of the right apical pulmonary lobe, followed by venous stasis and infarction (Fig. 6).

The necropsy was followed by opening of the abdominal cavity, where encountered changes were quite numerous. It was noticed the congestion of mesenteric lymph. At the liver level it was encountered the Glisson capsule fibrosis (Fig. $7)$. The rennet was without any digestive content and with superficial erosion (Fig. 8). On the rennet's surface, there were identified two lymph nodes (Fig. 9). The intestinal tract was congested, and the blood vessels presented a varicose aspect (Fig. 10). In the mesocolon, it was identified an oedematous mass, $13-15 \mathrm{~cm}$ in diameter.

At the head level, the main change was the congestion and cerebral oedema (Fig. 11).

The congenital defects are represented by structure and/ or function abnormalities present at birth. These can affect one single anatomic structure, parts of a system or an entire system, or in all cases, both the structure and function. These defects can be lethal (as in the present case), semilethal or in some cases they can be compatible with life, but the economic value of the animal is decreased.

There are three theories regarding the pathogenesis of this congenital defect: the primary

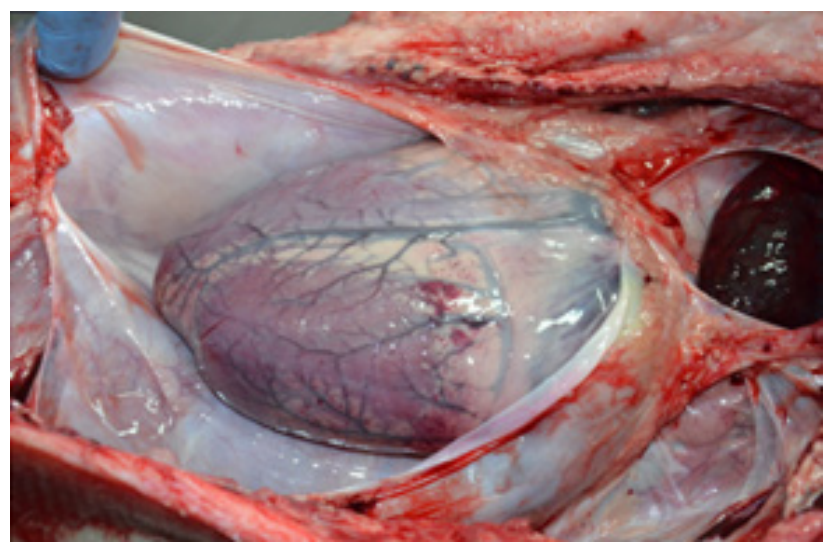

Fig. 3. Rounded apex, cranial-dorsal oriented 
failure of descending and fusion of median line with lateral folds of the body, the fusion failure of median line as a result of the early rupture of chorionic sac and the amniotic band syndrome (Abi and Giamberti, 2008).

In the majority of reported cases by different authors, the location, direction and heart shape were the same compared to our patient. A constant reported in all cases was the position of long axes of the heart, which was rotated with $180^{\circ}$ around the heart basis and the rounded shape of apex, the same changes found also in our case. In our case, the majority of blood vessels presented a varicose aspect, which was not reported in other cases

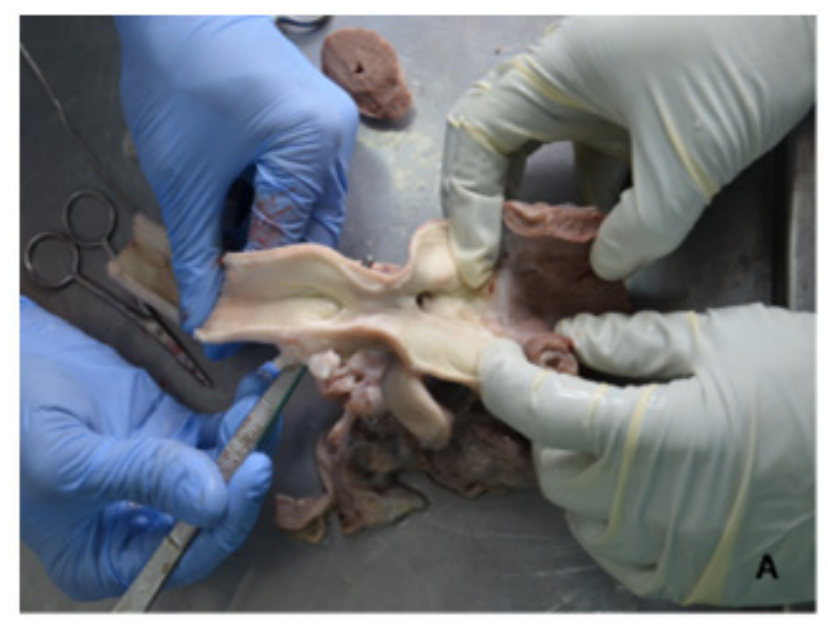

Fig. 4 A. Patent ductum arteriosus of cervical cardiac ectopia (Ciupercescu, 1986; Cârlan, 1996).

The breastbone abnormalities, such as shortening of its length, the hypoplasia of xifoid cartilage, the appearance of paired stern bras is frequently encountered in the case of heart ectopia. In our case, the breastbone was much narrowed and irregular.

The changes observed at the pulmonary level, liver and digestive tract were assumed that they appeared during the foetal development period due to the chronic congestive heart failure.

The prognosis in the case or our patient was serious, the patient died within two days after

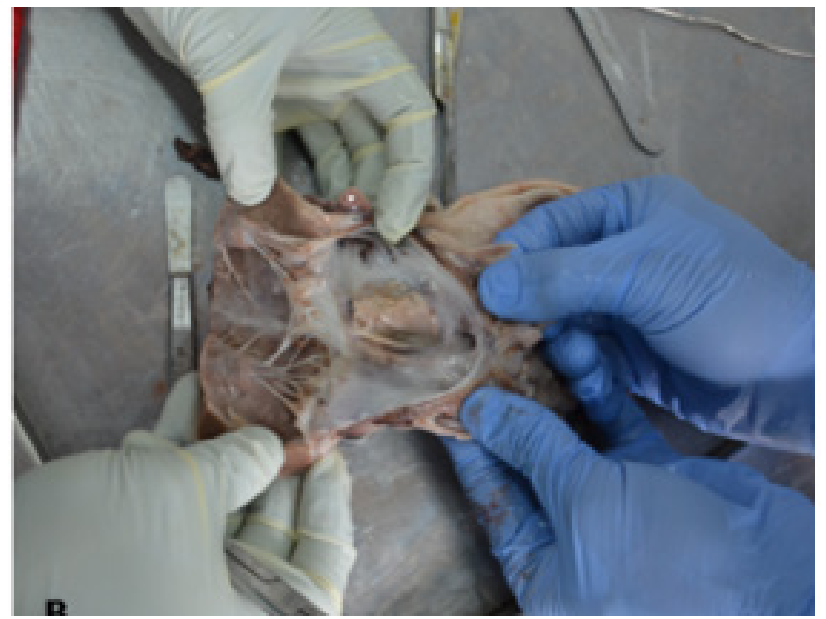

Fig. 4 B. Persistent interatrial hole

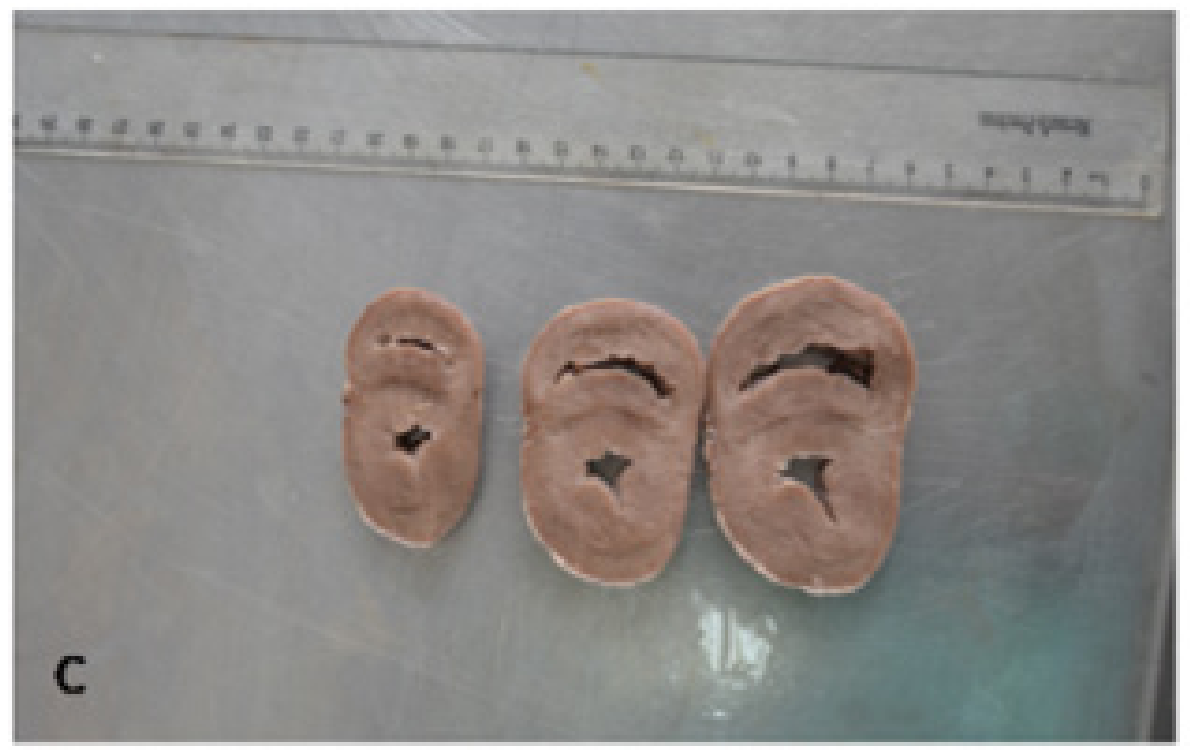

Fig. 4 C. Bilateral concentric cardiac hypertrophy 


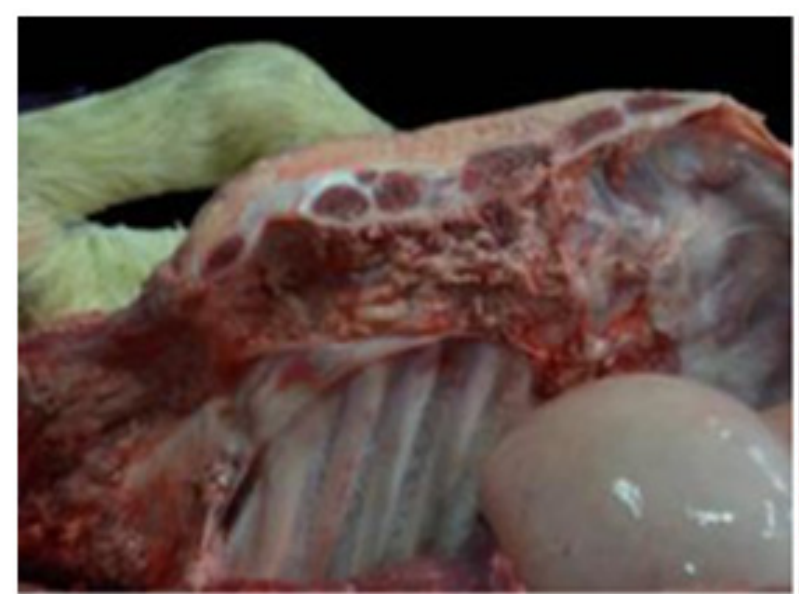

Fig. 5. The irregular aspect of the breastbone

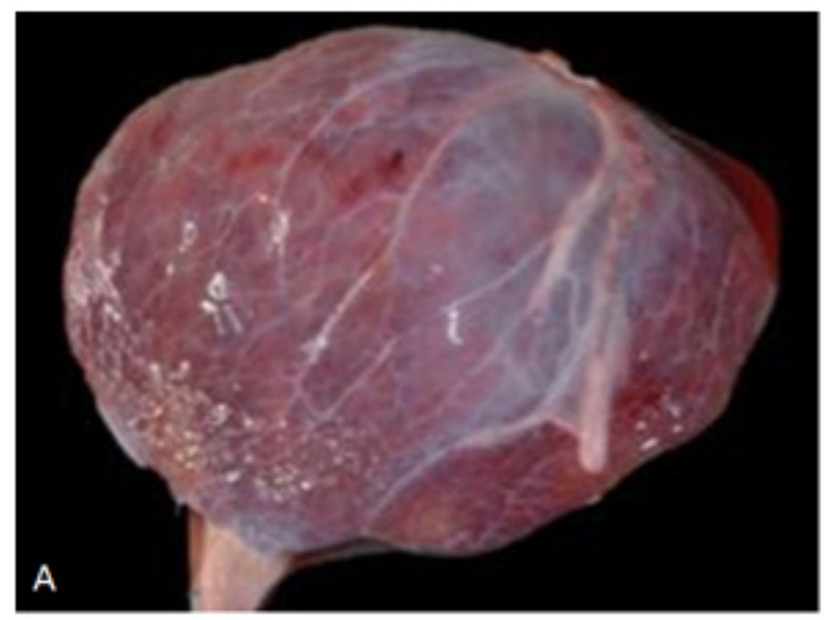

Fig. 7. Fibrosis of the Glisson capsule

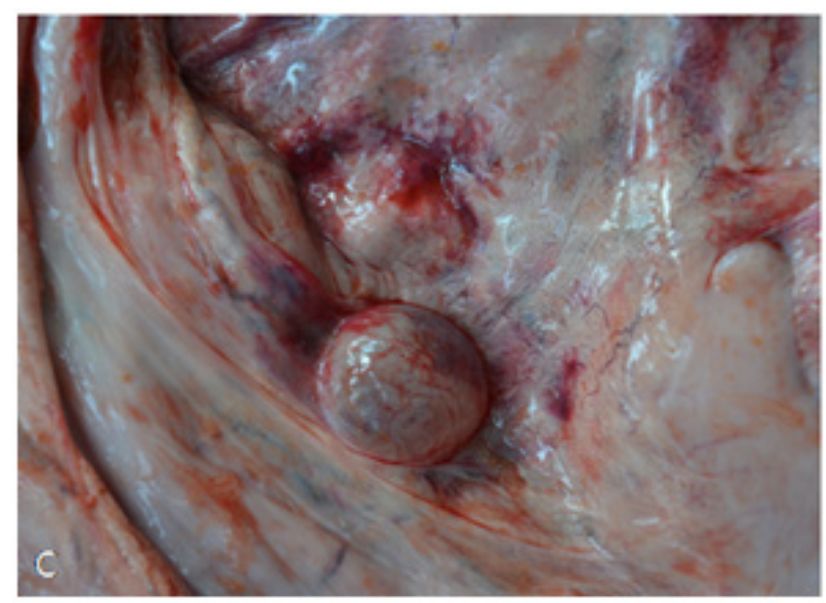

Fig. 9. Rennet - lymph nodes

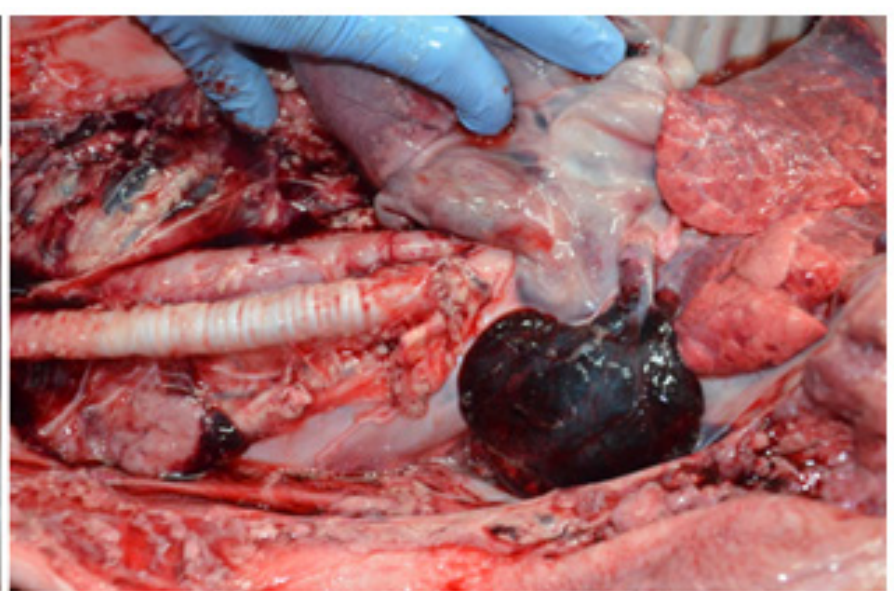

Fig. 6. Torsion of the right apical pulmonary lobe, congestion

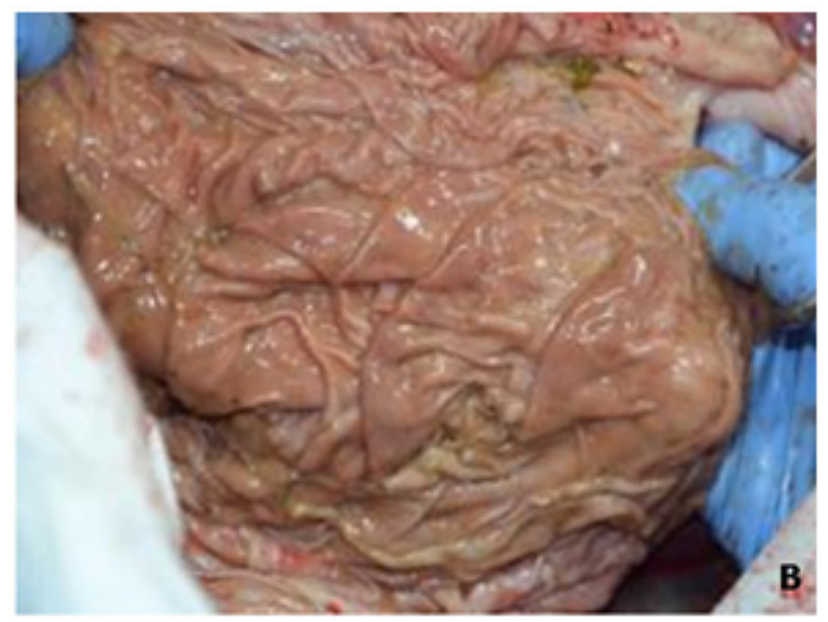

Fig. 8. Rennet- superficial erosion

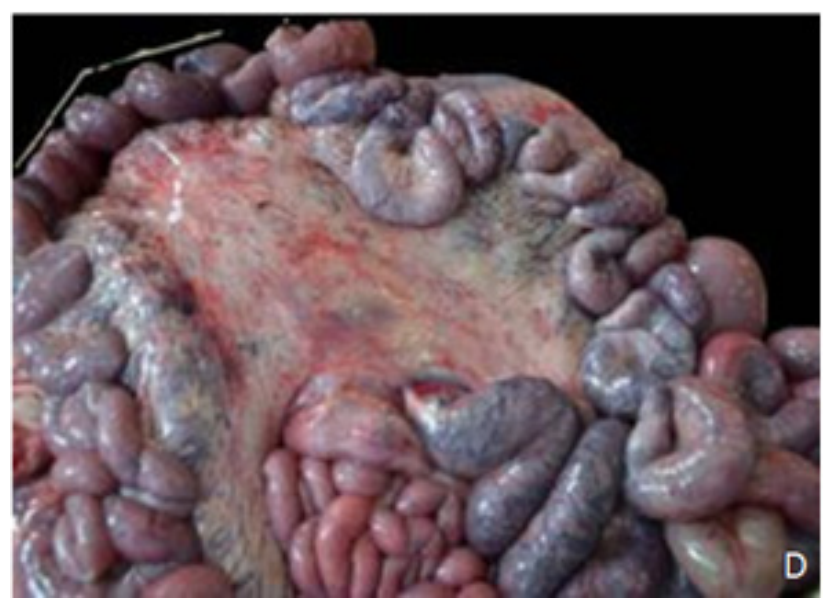

Fig. 10. Intestinal tract - varicose aspect 
birth. In some reported cases, the affected calf survived for months or even years. There is a case of a cow with cervical cardiac ectopia, which was pregnant at the age of 2 years and 5 months and the normal parturition was at 3 years and 1 month, and the calf was a healthy female, without any pathological changes (Ken et al., 2011).

In order to avoid the congenital pathological changes of this type it is very important to previously check the quality of sperm, both in the case of artificial insemination and also in case of the bulls used for insemination. It is very important, especially for the beef breeds (as in case of the above presented patient) to avoid the cross between brothers, half-brothers or between the parents and their offspring.

In the case of congenital malformations, the genetic prophylaxis measures are very important and they are very difficult to be applied in the case of a polygenic aetiology, but in the case of a recessive autosomal determinism the disorders are inherited according to the Mendelian pattern and there exist a program of very efficient prophylactic measures. These are represented by the control of the pairs, testcross for determination of the carriers of recessive genes and elimination from the genitor group of all the carriers of recessive genes.

\section{CONCLUSION}

In the case of our patient at palpation, the clinical examination emphasized a modified area in volume at the cervical level and the auscultation revealed the heartbeats. At necropsy, patent ductum arteriosus was diagnosed, together with the stenosis of aorta and bilateral heart hypertrophia.

Beside the heart changes, there were also changes in other organs, such as congestion of the mesenteric lymph, at the liver level it was encountered the Glisson capsule fibrosis, the rennet was without any digestive content and with superficial erosion, on the rennet's surface there were identified two lymph nodes, the intestinal tract was congested and the blood vessels presented a varicose aspect, in the mesocolon it was identified an oedematous mass of 13-15 cm in diameter.

In order to avoid these congenital pathological disorders is very important to previously check the quality of the sperm, also in the case of the bulls used for natural insemination. It is very important, especially for the beef breeds (as in case of the above presented patient) to avoid the cross between brothers, half-brothers or between the parents and their offspring.

In the case of the congenital malformations, it is recommendable to apply the genetic prophylaxis measures. In the case of a recessive autosomal determinism, the disorders are inherited according to the Mendelian pattern and there exist a program of very efficient prophylactic measures. These are represented by the control of the pairs, testcross for the determination of the carriers of the recessive genes and elimination from the genitor group of all the carriers of the recessive genes.

\section{REFERENCES}

1. Abi B, Giamberti A (2008). Ectopia Cordis: A case report and review of related embryology. Winter scientific meeting of British association of clinical anatomy, The School of Medicine, Health Policy and Practice, Norwich: University of East, UK.

2. Bowen JM , Adrian RW (1962). Ectopia cordis in cattle, J Am Vet Med Assoc 141:1162- 1167.

3. Ciupercescu DD (1986). Curs de genetică şi eredopatologie, ediţia a II-a, Tipo Agronomia, Cluj-Napoca.

4. Cîrlan VM (1996). Genetică şi eredopatologie - curs. Ed Universităţii Agronomice "Ion Ionescu de la Brad", Iaşi.

5. Hiraga T , Abe M (1986). Eight calves of cervical Ectopia cordis and their sternums. Jpn J Vet Sci 48:1199-1206.

6. Ken O, Masanori S, Keeko N, Reiichiro S, Sachiko A, Kazuyuki K, Seigo I, Makoto M, Tsunenori S, Yoshito W, Yasunori W (2011). Long-term survival of a cow with cervical ectopia cordis. Can Vet J 52(6):667-669.

7. Radostitis OM, Gay CC, Hinchcliff KW, Constable PD (2007). Veterinary medicine, $10^{\text {th }} \mathrm{Ed}$, WB Saunders Co, Spain, 432-434.

8. Wyrost P (1981). The results of studies on congenital cervical situs of the heart in domestic animals. Folia Morphol Praha 29:220-223. 